\title{
Oenlestatio
}

\section{A importância da Associação dos Arquivistas da Paraíba como instrumento de fortalecimento e visibilidade profissional}

\author{
Eloisa dos Santos Silveira \\ Bacharel; Universidade Estadual da Paraíba, Campina Grande, PB, Brasil; \\ elloisaa.santos@gmail.com \\ Claudialyne da Silva Araújo \\ Doutora; Universidade Federal da Paraíba, Campina Grande, PB, Brasil; \\ claudialynearaujo@gmail.com
}

\begin{abstract}
Resumo: Este estudo aborda como o associativismo profissional arquivístico tem sido discutido de forma mais recorrente entre as temáticas na área arquivística, sendo considerado atualmente como o principal percurso para o fortalecimento dessa classe profissional. Em particular, com este estudo busca-se avaliar a importância do associativismo profissional arquivista no estado da Paraíba. Adota-se uma abordagem qualiquantitativa de natureza descritiva, tomando como objeto de estudo os arquivistas formados no período de 2015 a 2018 na Universidade Estadual da Paraíba e na Universidade Federal da Paraíba, bem como os arquivistas filiados à Associação de Arquivistas da Paraíba. O instrumento de coleta de dados escolhido foi o Formulários Google, e os formulários foram aplicados via e-mail. Os Arquivistas, egressos das duas instituições, acreditam que o principal caminho para que a classe dos arquivistas se fortaleça é o associativismo, mas que o número de associados à Associação de Arquivistas da Paraíba, ainda é relativamente baixo, o que talvez se deva, de acordo com as respostas dos egressos ao fato de a associação ser relativamente discreta em suas atividades e não publicizar tanto as suas ações. $O$ associativismo é um caminho importante para a expansão da classe e deve ser abordado de forma mais recorrente. Além disso, às associações também precisam ser mais assíduas em difundir suas ações, tendo em vista obter um maior percentual de vinculados.
\end{abstract}

Palavras-chave: Associação de Arquivistas da Paraíba. AAPB. Associativismo. Arquivista. Visibilidade profissional.

\section{Introdução}

A sociedade pode ser entendida como um conjunto de pessoas ligadas pela conveniência social e cultural para cumprir suas obrigações e satisfazer suas necessidades, sejam elas de natureza material, afetiva ou espiritual (DALLARI, 2014). As relações sociais e coletivas são a base da pirâmide cultural implementada pelo conjunto de organizações previamente estabelecidas pela ordem comunitária fixada pelos pares. As representações sociais, assim, são criadas para compreendermos, gerenciarmos ou afrontarmos algo já existente (JODELET, 2001). 
O associativismo arquivístico no Brasil teve início nos anos 1970, com a criação da Associação dos Arquivistas Brasileiros (AAB) em 1971. Desde então, a profissão foi institucionalizada e foram criados, aos poucos, os cursos de Arquivologia a nível superior e as associações de arquivistas existentes no país. Esta pesquisa tem como objetivo geral analisar a importância do associativismo profissional arquivista no estado da Paraíba. Os objetivos específicos são: investigar as opiniões dos egressos da Universidade Estadual da Paraíba (UEPB) e da Universidade Federal da Paraíba (UFPB) a respeito do associativismo arquivístico e da Associação dos Arquivistas da Paraíba (AAPB); identificar as formas de atuação dessa associação no estado e propor melhorias com base nas opiniões dos egressos; verificar a quantidade de egressos dessas universidades e de arquivistas em geral filiados à AAPB, e ressaltar a importância das associações arquivistas para a consolidação da categoria, assim como também a criação do Conselho Federal de Arquivologia. Este estudo se justifica por conta dessa importância, manifesta na maior representatividade que as associações profissionais garantem para as suas categorias.

A pesquisa tem uma abordagem qualiquantitativa, tomando como objeto da pesquisa os arquivistas formados pela UEPB e UFPB no período de 2015 a 2018, bem como os que compõem a AAPB. A temática proposta está relacionada com a área de visibilidade profissional dentro da Arquivologia. Diante das lacunas encontradas com relação ao conteúdo abordado, pretende-se ressaltar o papel do arquivista no fortalecimento de sua classe e na criação de um Conselho Federal de Arquivologia.

\section{Associativismos, cooperativismo e sindicalismo}

O associativismo pode ser entendido como um movimento por parte de uma classe, seja de trabalhadores, comerciantes, estudantes ou pessoas, de um modo geral, que se congregam em associações para a defesa de seus interesses. De acordo com o Serviço Brasileiro de Apoio às Micro e Pequenas Empresas (SEBRAE) (SEBRAE, 2019), o associativismo é um instrumento importante para que uma comunidade saia do anonimato e passe a ter maior expressão social, política, ambiental e econômica. As autoras Santos e Silva (2018, p. 688), a respeito disso, apontam:

O associativismo dos arquivistas teve início, no Brasil, nos anos 70, com criação da Associação dos Arquivistas Brasileiros (AAB), constituída como sociedade civil de direito privado e instituída para dignificar socialmente a profissão arquivista e contribuir para o desenvolvimento da Arquivologia no país. Esse foi um período significativo, uma vez que a AAB tinha o objetivo de institucionalizar o Curso de Graduação em Arquivologia no Brasil e o arquivista. A partir desse movimento, a 
profissão de arquivista foi regulamentada pela Lei $\mathrm{n}^{\circ}$. 6.546, de 04 de julho de 1978. (SANTOS; SILVA, 2018, p. 688).

De acordo com Souza (2011), o associativismo não é um tema recorrente na área arquivística: os estudos existentes narram os processos de associativismo e mercado laboral e de associativismo e visibilidade profissional. Porém, a temática deve ser abordada de forma mais recorrente, pois, na ausência de um conselho federal, as associações profissionais é que devem desempenhar o papel de representantes dos interesses da categoria.

A autora Hahn Lüchmann (2014) explica que o associativismo é uma forma de democracia que reduz os comportamentos oportunistas, produzindo práticas de colaboração conjunta, que sustentam vida democrática. Conforme o Serviço Nacional de Aprendizagem Rural (SENAR) (SENAR, 2015), o cooperativismo pode ser entendido como um movimento capaz de unir desenvolvimento econômico e bem-estar social. É um sistema fundamentado na reunião de pessoas e não no capital, visando não ao lucro nem à prosperidade individual, mas às necessidades do grupo e à prosperidade conjunta.

Segundo o SEBRAE (2019), as associações são indicadas para levar adiante uma atividade social e têm como finalidade: a assistência social, educacional e cultural; a representação política; a defesa de interesses de classe e a filantropia. As cooperativas, por sua vez, têm um objetivo essencialmente econômico; a saber, viabilizar o negócio produtivo dos associados no mercado. O SENAR (2015) aponta que o sindicalismo pode ser entendido como um movimento social de associação de profissionais em grupos que representam seus interesses trabalhistas e políticos, como forma de organização e luta dos trabalhadores pelos seus direitos trabalhistas e políticos.

Segundo Cesário (2017), as associações e sindicatos são pessoas jurídicas de direito privado, sem fins lucrativos, que reúnem indivíduos com os mesmos interesses. As associações atuam apenas em nome de seus associados, enquanto o sindicato trabalha em prol de toda a categoria profissional ou econômica, independentemente de filiação. Dessa forma, tanto o associativismo como o cooperativismo e o sindicalismo podem ser compreendidos como movimentos organizados em prol de determinados grupos com os mesmos interesses. 


\section{Associações profissionais e sua importância para o fortalecimento da classe}

A sociedade é constituída por pessoas que, a todo o momento, tomam decisões baseadas em seus interesses. Assim, com a união e os esforços dos que compartilham do mesmo propósito, é possível alcançar os objetivos traçados, de maneira mais forte e efetiva (SENAR, 2015).

De acordo com o Art. 53 da Lei Federal n 10.406, de 10 de janeiro de 2002, "Constituem-se as associações pela união de pessoas que se organizem para fins não econômicos" (BRASIL, 2002). As associações têm o papel de representar determinado grupo social, atuando de modo a facilitar o exercício de uma profissão e a promover a educação, a cultura, a política e os interesses comuns de determinadas classes, regiões ou setores. E de acordo com Souza (2011), os coletivos profissionais podem e devem atuar na indicação e elaboração de estudos de mercado de maneira a contribuir com o reconhecimento dos profissionais por parte da sociedade.

Segundo Reis (2006), nos anos 1960 surgiu uma maior preocupação com a práxis arquivística, o que acentuava a vertente técnica da área. E na década de 1970, cresceu a preocupação com a consolidação de um corpo teórico, no sentido de ampliar o domínio da área, de modo que as pessoas pudessem enxergar a Arquivística não apenas como uma técnica, porém sim um domínio do saber mais geral.

De acordo com Marques, Rodrigues e Nougaret (2018), o Arquivo Nacional ofertou o primeiro curso relacionado à arquivologia, o "Curso Permanente de Arquivos - CPA", em 1960. As autoras consideram a década de 1970 como um divisor de águas na trajetória da arquivologia brasileira, apontando diversos marcos, como a criação da AAB e da Associação de Pesquisa Histórica e Arquivística (APHA); a realização do I Congresso Brasileiro de Arquivologia (CBA); a autorização da criação de cursos de Arquivologia em nível superior, pelo Conselho Federal de Educação (CFE); o reconhecimento da arquivologia como habilitação profissional no ensino médio; o estabelecimento da duração do curso superior de arquivologia e do seu currículo mínimo e a regulamentação das profissões de arquivista e técnico de arquivo.

Segundo Fonseca (2005), a criação dos cursos de Arquivologia em nível superior no Brasil remonta a 24 de janeiro de 1972, com o voto da Câmara de Ensino Superior que aprovou a criação desses cursos. Essa conquista só foi possível graças à criação da Associação dos Arquivistas Brasileiros (AAB) em 1971, que hoje não mais existe.

De acordo com informações obtidas no site de Arquivologia da UEPB (2020), o primeiro curso criado foi o da Universidade Federal do Estado do Rio de Janeiro (UNIRIO), 
em 1973. Posteriormente, surgiram os cursos: na Universidade Federal de Santa Maria (UFSM), em 1977; na Universidade Federal Fluminense (UFF), em 1978; na Universidade de Brasília (UnB), em 1990; na Universidade Estadual de Londrina (UEL) e na Universidade Federal da Bahia (UFBA), em 1998; na Universidade Federal do Rio Grande do Sul (UFRGS), em 1999; na Universidade Federal do Espírito Santo (UFES), em 2000; na Universidade Estadual Paulista (UNESP/Marília), em 2003; na Universidade Estadual da Paraíba (UEPB), em 2006; na Universidade Federal da Paraíba (UFPB), na Universidade Federal de Minas Gerais (UFMG), na Universidade Federal do Amazonas (UFAM) e na Universidade Federal do Rio Grande (FURG), em 2008; na Universidade Federal de Santa Catarina (UFSC), em 2010, e por fim na Universidade Federal do Pará (UFPA), em 2012 Atualmente, no Brasil, existem ao todo 16 cursos superiores de Arquivologia (ARQUIVOLOGIA UEPB, 2020).

Também no Brasil, de acordo com dados da pesquisa, coletados através das home pages, páginas do facebook, contato via mensagem e e-mail direcionados às associações arquivistas, atualmente existe o total de treze associações arquivísticas. A Região Norte é a que possui o menor número, apenas uma associação a Associação dos Arquivistas do Estado do Pará (AAEPA), criada em 2019. A Região Nordeste, assim como as demais, possui três associações: a Associação dos Arquivistas da Bahia (AABA) criada em 2002; a Associação dos Arquivistas da Paraíba (AAPB), criada em 2013; e a Associação de Arquivistas do Estado do Ceará (ARQUIVE-CE), criada em 2015.

Região Centro-Oeste: Associação Brasiliense de Arquivologia (Abarq), criada em 1998; a Associação de Arquivologia do Estado de Goiás (AAG), criada em 2006; e a Associação Mineira de Arquivistas (AMArq), criada em 2013. Região Sudeste: a Associação de Arquivistas de São Paulo (ARQ-SP), criada em 1998; a Associação dos Arquivistas do Estado do Espírito Santo (AARQES), criada em 2005; e a Associação dos Arquivistas do Estado do Rio de Janeiro (AAERJ), criada em 2004. E a Região Sul: a Associação de Arquivistas do Estado de Santa Catarina (AAESC), criada em 2015; a Associação dos Arquivistas do Rio Grande do Sul (AARS), criada em 1999; e a Associação Paranaense de Arquivistas (APA), criada em 2006.

A criação dos cursos de Arquivologia deixa notória a necessidade de profissionais qualificados nessa área no mercado de trabalho e mostra ainda que o arquivista é um especialista polivalente, que pode desempenhar várias atividades e que, aos poucos, tem conquistado espaço no mercado de trabalho. Assim, a criação das associações torna 
perceptível a necessidade de defesa dos interesses dessa classe que vem crescendo e ganhando destaque. Na ausência e um Conselho Federal de Arquivologia, as associações têm desempenhado um papel relevante na fiscalização do exercício da profissão.

Dessa forma, é possível perceber que, na maioria dos estados em que há curso de Arquivologia, ou seja, estados onde são formados esses profissionais, foram fundadas associações arquivistas, com exceção dos estados do Ceará e de Goiás, nos quais, ainda que não haja curso de Arquivologia, já deve existir, assim como nos demais estados, uma demanda por representatividade social arquivística.

Segundo Calderon e colaboradores (2004), é necessária, à frente da gestão dos arquivos, a presença de arquivistas, profissionais preparados para responder às necessidades do arquivo e de seus usuários internos e/ou externos que buscam informações para a elaboração de seus trabalhos e pesquisas.

Um ponto relevante nesse sentido é a Lei Federal nº 6.546, de 4 de julho de 1978, que dispõe sobre a regulamentação das profissões de Arquivista e de Técnico de Arquivo, e dá outras providências de modo a estabelecer e fazer separação entre suas atribuições:

Art. $2^{\circ}$ - São atribuições dos Arquivistas:

I - planejamento, organização e direção de serviços de Arquivo;

II - planejamento, orientação e acompanhamento do processo documental e informativo;

II - planejamento, orientação e direção das atividades de identificação das espécies documentais e participação no planejamento de novos documentos e controle de multicópias;

IV - planejamento, organização e direção de serviços ou centro de documentação e informação constituídos de acervos arquivísticos e mistos;

V - planejamento, organização e direção de serviços de microfilmagem aplicada aos arquivos;

VI - orientação do planejamento da automação aplicada aos arquivos;

VII - orientação quanto à classificação, arranjo e descrição de documentos;

VIII - orientação da avaliação e seleção de documentos, para fins de preservação;

IX - promoção de medidas necessárias à conservação de documentos;

X - elaboração de pareceres e trabalhos de complexidade sobre assuntos arquivísticos;

XI - assessoramento aos trabalhos de pesquisa científica ou técnico-administrativa;

XII - desenvolvimento de estudos sobre documentos culturalmente importantes.

Art. $3^{\circ}$ - São atribuições dos Técnicos de Arquivo:

I - recebimento, registro e distribuição dos documentos, bem como controle de sua movimentação;

II - classificação, arranjo, descrição e execução de demais tarefas necessárias à guarda e conservação dos documentos, assim como prestação de informações relativas aos mesmos;

III - preparação de documentos de arquivos para microfilmagem e conservação e utilização do microfilme;

IV - preparação de documentos de arquivo para processamento eletrônico de dados. (BRASIL, 1978). 
Observa-se, assim, uma separação entre a atuação dos técnicos de arquivo e a atuação dos arquivistas. Além disso, como atualmente não há um órgão que fiscalize o exercício da profissão, podem atuar como técnicos de arquivo portadores de certificados de conclusão de ensino de $2^{\circ}$ grau que, no entanto, "recebam treinamento específico em técnicas de arquivo em curso ministrado por entidades credenciadas pelo Conselho Federal da Mão-de-Obra, do Ministério do Trabalho, com carga horária mínima de 1.110 horas nas disciplinas específicas.” (BRASIL, 1978). Ou seja, qualquer pessoa que não possua uma qualificação adequada na área de Arquivologia pode atuar dentro dos arquivos, pois alguns editais exigem apenas o nível técnico

Embora o arquivista ainda não tenha a mesma visibilidade que outros profissionais da informação, como o bibliotecário, um ponto relevante que tem tornado a profissão um pouco mais visível, além dos já citados, como a Lei Federal nº 6.546 de 1978, é a Lei Federal no 12.527 de 18 de novembro de 2011, mais conhecida como Lei de Acesso à Informação (LAI), que regula o acesso a informações (BRASIL, 2011). Para que os usuários tenham acesso à informação de forma rápida e segura e para que a informação possa ser recuperada de maneira eficaz, são necessários acervos bem geridos.

Assim, para que a classe arquivista obtenha uma maior visibilidade e tenha garantias quanto ao exercício da profissão, de forma resguardada, é necessária a criação de um conselho federal e conselhos regionais de Arquivologia, que tenham como principais funções fiscalizar o exercício da profissão. De acordo com o website do Conselho Regional de Biblioteconomia da $15^{\text {a }}$ Região (CRB-15) (2019), os conselhos regionais de Biblioteconomia têm por objetivos básicos fiscalizar o exercício da profissão e contribuir para o aprimoramento da área e de seus profissionais em níveis regionais e têm suas atividades diretamente articuladas com o Conselho Federal de Biblioteconomia.

Os conselhos federal e regionais de Biblioteconomia, por sua vez, reforçam que, para exercer legalmente a profissão, é obrigatório, ainda, o registro do profissional no respectivo conselho regional, assim como ocorre com outros profissionais liberais, como médicos, advogados e arquitetos. O CRB-15 (2019) afirma que os conselhos regionais atuam no que se refere aos interesses dos bibliotecários como exercendo ações administrativas, normativas, supervisoras e disciplinares têm por finalidades gerais: zelar pelo bom conceito da profissão; orientar e defender o livre exercício da profissão; julgar infrações à lei e à ética e servir como órgão consultivo do governo federal, devido aos conselhos regionais estarem diretamente e hierarquicamente ligados ao conselho federal e o conselho federal subordinado a Federação. 
Dessa forma, podemos perceber que as associações arquivistas, além de desempenhar suas funções, têm desempenhado também o papel desses órgãos, buscando de alguma forma fiscalizar o exercício da profissão e defendendo de forma geral os interesses da classe, como é o caso da $\mathrm{AAPB}$, que busca sempre vetar as vagas de concursos que não exigem nível superior para o cargo de arquivista, lutando por melhores salários para os arquivistas, por seu reconhecimento profissional e por mais abertura no mercado de trabalho, como veremos mais à frente.

\section{Associação dos Arquivistas da Paraíba (AAPB): origens e atuação}

Conforme a home page da AAPB (2019), essa associação é uma entidade privada, sem fins lucrativos, que visa congregar arquivistas, profissionais de arquivo e estudantes de Arquivologia. A AAPB teve seus primeiros diálogos em meados de 2010, mas sua fundação só ocorreu no dia 19 de novembro de 2013, com a primeira Assembleia Geral, contando com a participação de arquivistas e profissionais da área, professores e estudantes de Arquivologia.

Entre os anos de 2010 e 2011, ocorreram duas reuniões e, no ano de 2012, foi realizada a terceira reunião, em que se retomaram as discussões com o intuito de fundar a AAPB. A partir disso, foi constituída a Comissão Provisória, composta por doze membros eleitos responsáveis pela elaboração do estatuto de fundação. No dia 17 de setembro de 2015, ocorreu a primeira eleição para escolha da Diretoria Executiva, Conselho de Ética e Conselho Fiscal para o biênio 2015/2017.

A AAPB tem como objetivos: congregar arquivistas e profissionais que atuam e desenvolvem atividades que se relacionam aos arquivos e à arquivologia, defendendo seus interesses; cooperar com entidades públicas e privadas, nacionais e estrangeiras, na solução de problemas relacionados aos arquivistas, aos arquivos e à arquivologia; organizar congressos, conferências, palestras, simpósios, mesas redondas, seminários, reuniões, encontros e outros eventos que contribuam para o desenvolvimento e o aperfeiçoamento profissional no campo da Arquivologia; colaborar, quando solicitada, na medida de suas possibilidades, nos eventos promovidos por entidades afins; publicar e divulgar literatura e documentação técnicocientífica de interesse da área; manter intercâmbio profissional, cultural, técnico-científico e social com entidades congêneres no país e no exterior.

Promover cursos para atualização, capacitação e aprimoramento técnico dos arquivistas e profissionais de arquivo; conferir títulos, certificados, prêmios e láureas a profissionais que se destacarem no campo da Arquivologia; organizar e manter atualizado o 
sistema de informação técnico-científica, bem como o cadastro dos profissionais que atuam na área; fazer-se representar por seu presidente em exercício ou por outro membro da diretoria assim indicado, perante todas as entidades congêneres; desenvolver e divulgar projetos culturais (AAPB, 2019).

A AAPB possui uma home page bem estruturada e de fácil compreensão, em que estão disponíveis todas as informações sobre as formas de filiação e sobre a associação, seus parceiros e formas de atuação. Ela possui as seguintes categorias de filiação: estudantes; técnicos em arquivo; arquivistas; professores e empresas.

\section{Metodologia}

Metodologicamente, esta pesquisa tem abordagem qualiquantitativa, de natureza descritiva e exploratória, em busca de compreender o processo de associativismo arquivístico no estado da Paraíba, tomando como objeto de estudo os arquivistas formados pela UEPB e UFPB, como também a AAPB, no recorte de tempo de 2015 a 2018.

O método de coleta de dados utilizado foi o Formulário Google, de forma semiestruturada. O formulário é um instrumento de coleta de dados constituído de uma lista de questões previamente elaboradas e ordenadas para o propósito da pesquisa (MICHEL, 2009). Os formulários foram aplicados via e-mail aos arquivistas formados pela UEPB e UFPB no período de 2015 a 2018, e à AAPB. O recorte temporal escolhido se deu devido ao fato de que a AAPB apenas começou a vigorar (oficializar) suas atividades a partir de 2015, quando ocorreu a $1^{\mathrm{a}}$ eleição para escolha da Diretoria Executiva, Conselho de Ética e Conselho Fiscal. Desse modo, os dados coletados e analisados coadunam com o período de atuação da Associação no estado da Paraíba.

Para tanto, foi solicitada às coordenações de Arquivologia da UEPB e UFPB uma lista com os respectivos e-mails dos egressos. A coordenação da UEPB nos enviou uma lista com 228 e-mails e a UFPB com 193. O processo de coleta de dados ocorreu no período de 21 de maio a 28 de outubro de 2019. Os e-mails foram selecionados aleatoriamente e enviados 30 questionários aos egressos de cada universidade, quantidade de amostra assim definida devido ao tempo disponível para coleta e análise dos dados. Dos 30 e-mails enviados aos egressos da UEPB, obtivemos 12 respostas e, dos 30 enviados aos egressos da UFPB, obtivemos 8 respostas. Foi realizada, ainda, uma pesquisa nas páginas oficiais/redes sociais das associações, para o levantamento dos dados no que diz respeito ao ano em que cada associação foi fundada. 
O formulário aplicado aos arquivistas teve o objetivo de investigar e identificar o quantitativo de profissionais que são conhecedores do que é a AAPB e qual sua função; se esses conhecem como se dá o processo de vinculação e as formas de atuação da AAPB; o percentual de filiados; e as possíveis causas por que esses profissionais ainda não possuem esse vínculo. Para facilitar o processo de análise dos dados, utilizamos o método de Análise de Categorias, e dividimos as questões em três blocos: 1) dados sociodemográficos; 2) associativismo e 3) AAPB.

\section{Resultados e discussões}

Iremos analisar os dados coletados junto aos egressos das Universidades Estadual e Federal da Paraíba e, posteriormente, os dados coletados junto à Associação dos Arquivistas da Paraíba. Para representar os respondentes da UEPB, será utilizada a letra E, a exemplo: E1 para respondente 1 da UEPB. Para representar os respondentes da UFPB, será utilizada a letra F, a exemplo: F1 para o respondente 1 da UFPB. A AAPB, por sua vez, será representada através de: R.A, que será o mesmo que representante da AAPB.

\subsection{Dados sociodemográficos}

Inicialmente, procuramos identificar o perfil dos egressos, a fim de verificar se esses estão ou não atuando como arquivistas e, caso não estejam, o porquê. A partir disso, foi feito o seguinte questionamento: "Você está atuando como arquivista"? A seguir, o gráfico com as respostas em "sim" ou "não", sobre se os egressos estão atuando como arquivistas:

Gráfico 1: Se os egressos estão atuando como arquivistas 


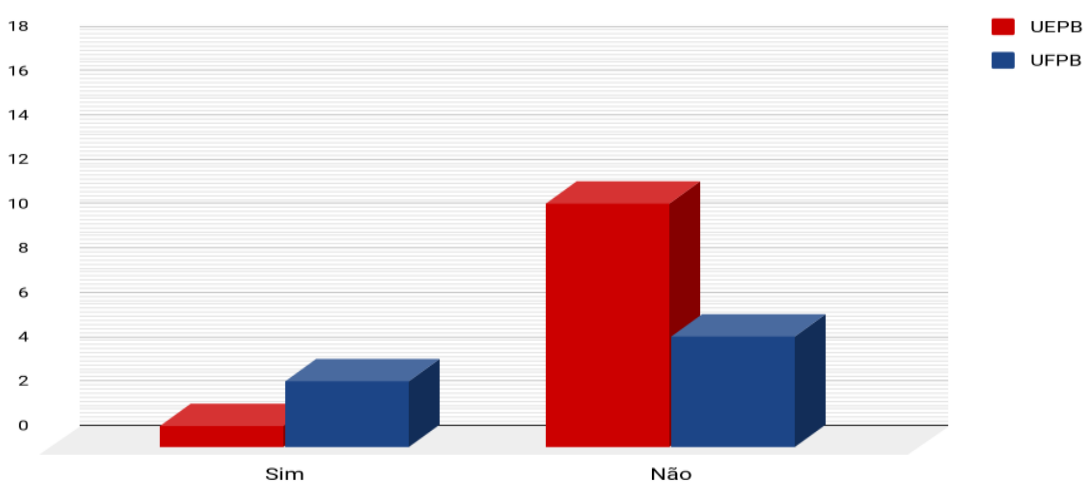

Fonte: Dados da Pesquisa, 2019.

De acordo com o gráfico, é possível perceber que a maioria dos respondentes ainda não está atuando como arquivista, constatando que apenas 4 dos 20 respondentes estão atuando na área. Um percentual baixo, a considerar que o estado possui dois cursos que formam arquivistas, há 10 anos.

Foi questionado também: "Caso a resposta anterior tenha sido sim, qual o nome da instituição em que você está trabalhando? Caso a resposta tenha sido não, justifique o porquê de não estar atuando como arquivista". Os egressos que responderam afirmativamente disseram estar trabalhando nas seguintes instituições: Prefeitura Municipal de Serra Talhada (PB), Associação dos Docentes da UFPB - ADUFPB, Fundação Universidade Federal do Amapá - UNIFAP e um dos respondentes não apontou a instituição.

Sobre os egressos da UEPB que responderam não estar atuando na área, E7 alegou ser estudante de pós-graduação; o respondente E5 afirmou ter interesse em ingressar na pósgraduação; os respondentes E2 e E9 disseram estar atuando em cargos distintos; E4, E6, E8 e E10 não justificaram e os respondentes E1 e E12 responderam que não estão atuando por falta de oportunidade. Dos 5 egressos da UFPB que não estão atuando como arquivistas, o respondente $\mathrm{F} 3$ disse ter sido contratado como técnico de arquivo e os respondentes F1, F4 e F7 apontaram a questão da falta de oportunidade e do mercado ser pouco valorizado.

\subsection{Associativismo}

Outro questionamento realizado foi: "Você sabe o que é ou já ouviu falar sobre associativismo profissional?", visando identificar se os egressos tinham conhecimento sobre a temática. A seguir, o gráfico indicando as respostas: 
Gráfico 2: O que é Associativismo Profissional

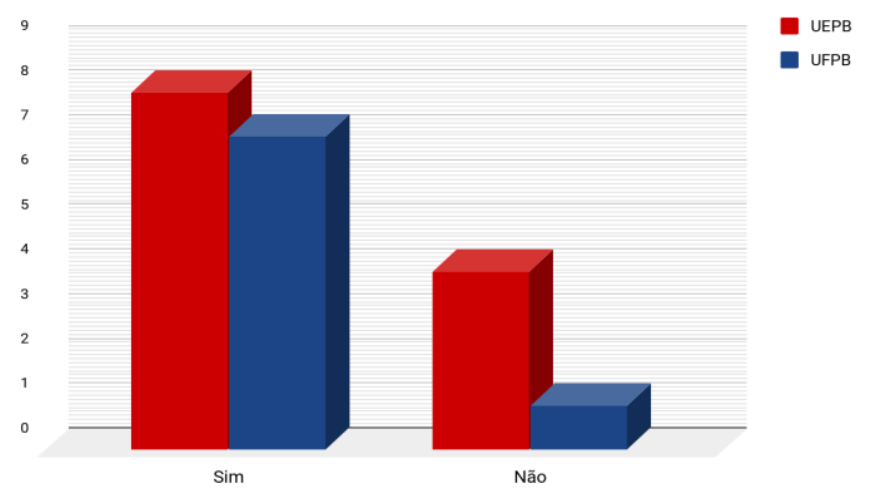

Fonte: Dados da Pesquisa, 2019.

Os dados apontaram que a maioria, 8 a cada 12 respondentes da UEPB e 7 a cada 8 da UFPB, tem conhecimento sobre o que é associativismo profissional, porém 4 da UEPB e 1 da UFPB afirmaram não ter conhecimento sobre o que se trata, totalizando 5 dos 20 participantes, o que talvez ocorra devido à literatura arquivística sobre mercado laboral ser escassa e ao tema ter pouca incidência (SOUZA, 2011).

Posteriormente, foi questionado: "Na sua opinião, o associativismo profissional seria o melhor caminho para o fortalecimento da classe arquivista, visando à criação do Conselho Federal de Arquivologia, Sim ou Não?” A seguir, o gráfico com as respostas:

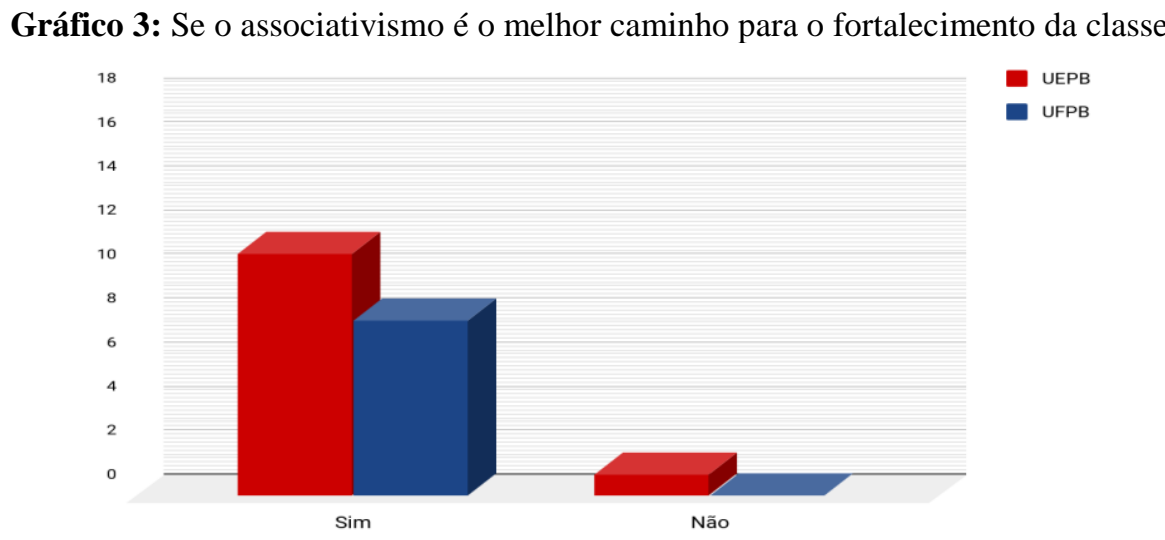

Fonte: Dados da Pesquisa, 2019.

A maioria dos participantes respondeu "sim", porém é necessário que haja uma maior adesão, pois, "as associações, através da adesão de pessoas cujos interesses estão em um mesmo fim, convergem para o atendimento das aspirações dos seus associados" (ALMEIDA; FEITOZA; FELIX, 2018, p. 718). 


\subsection{Associação dos Arquivistas da Paraíba - AAPB}

Procuramos investigar se os egressos conhecem a AAPB e, para isso, foi feito o seguinte questionamento: "Você conhece ou já ouviu falar sobre a Associação dos Arquivistas da Paraíba-AAPB?” A seguir, o gráfico com os dados expostos:

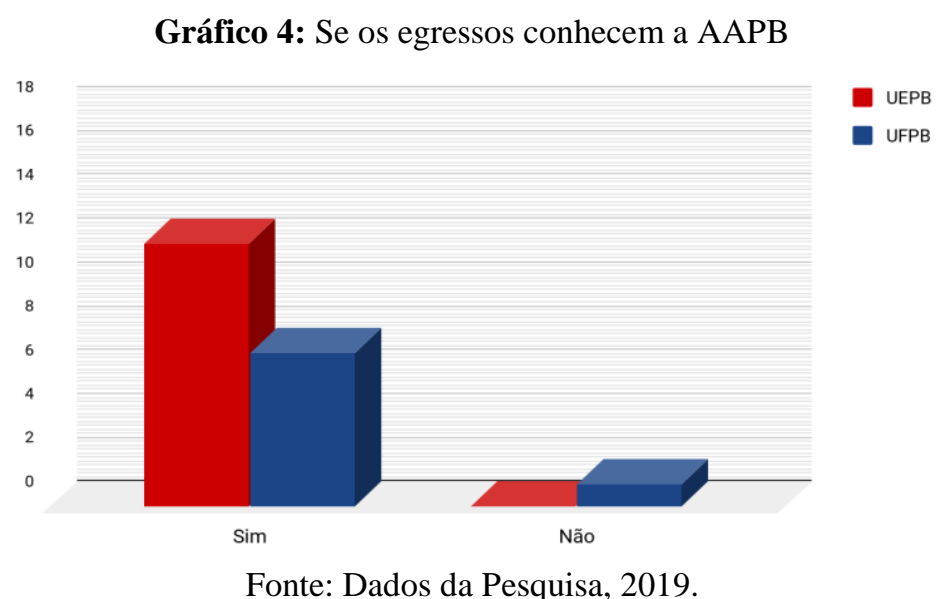

Quase em unanimidade, os egressos responderam "sim", com exceção apenas do participante $\mathrm{F} 4$, que alegou não conhecer.

Posteriormente, foi questionado: "Você possui vínculo com a AAPB ou com alguma outra associação?” A seguir o gráfico:

Gráfico 5: Se os egressos possuem vínculo com a AAPB ou com alguma outra associação

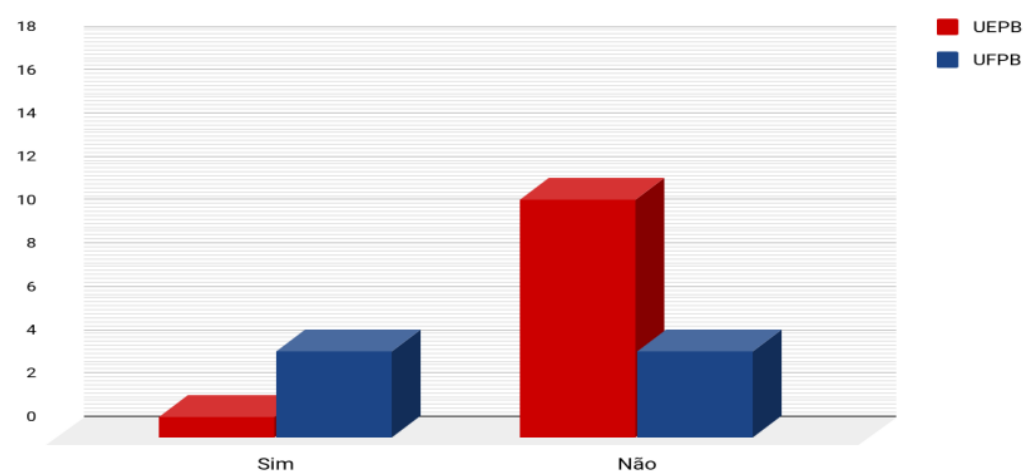

Fonte: Dados da Pesquisa, 2019

Os dados acima demonstram que o número de adesão AAPB, com base nas respostas, ainda é baixo, principalmente por parte dos egressos da UEPB, pois apenas 1 de 12 egressos (o respondente E5) afirmou possuir vínculo com a AAPB. Quanto às respostas dadas pelos egressos da UFPB, o número de vinculados se mostrou razoável, sendo 4 vinculados a cada 8 respondentes. 
Posteriormente, foi questionado: "Caso sua resposta anterior tenha sido sim, para AAPB, você acompanha as atividades desenvolvidas por essa Associação?", em busca de identificar se os egressos têm algum interesse nessas atividades. A seguir, o gráfico com os resultados:

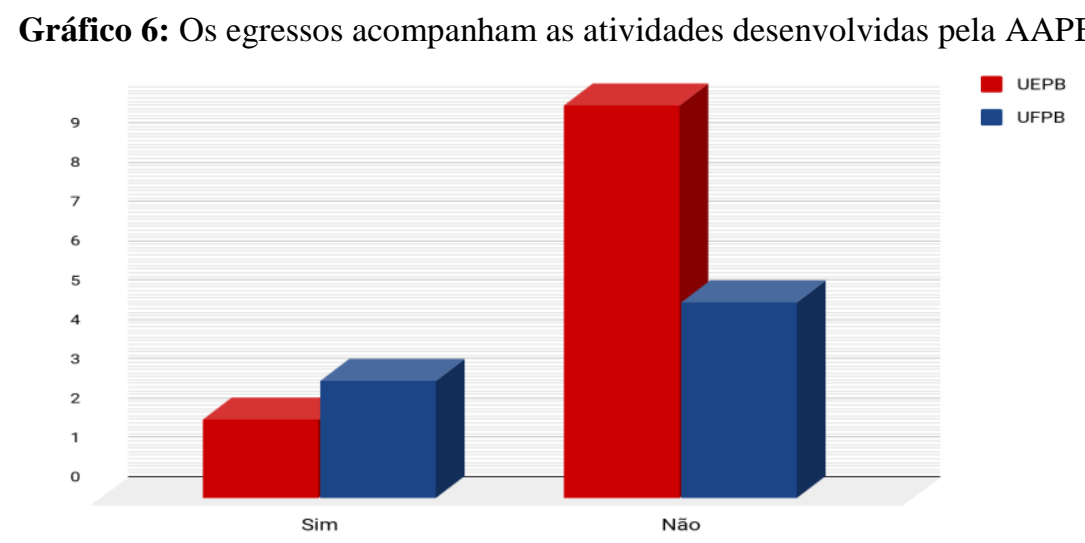

Fonte: Dados da Pesquisa, 2019.

Os dados apontaram que 5 dos 20 respondentes acompanham as atividades da AAPB, sendo 2 a cada 12 regressos da UEPB e 3 a cada 8 da UFPB. Os dados apontaram ainda que 2 dos 5 respondentes que alegaram ser vinculados à AAPB, os respondentes F5 e F6, não acompanham as atividades, e que os respondentes E7 e F1, mesmo não sendo vinculados, acompanham.

Segundo Souza (2011, p. 156), "A interação dos arquivistas com os coletivos profissionais é mais frequente quando o profissional considera que a associação estabelece ações que o ajudam a ser reconhecido profissionalmente", o que, dessa maneira, nos permite perceber que a AAPB necessita interagir mais com seu público-alvo, de forma que a maioria dos egressos tenha um maior interesse e interaja com a Associação.

Foi investigada também a opinião dos egressos no que diz respeito à atuação da AAPB, para verificar se, na visão deles, ela tem contribuído quanto ao aumento da visibilidade profissional da Classe Arquivista. A seguir, o gráfico com o quantitativo das respostas a respeito da contribuição da AAPB para a classe: 
Gráfico 7: Se a AAPB tem contribuído com o aumento da visibilidade da Classe Arquivista

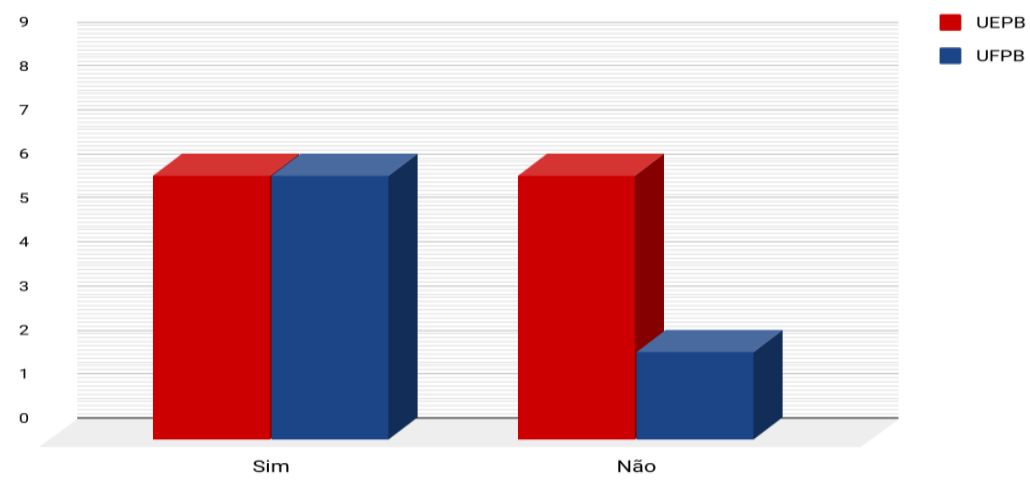

Fonte: Dados da Pesquisa, 2019.

Os dados acima apontam que metade dos respondentes da UEPB acredita e metade discorda que a AAPB tem contribuído com o aumento da visibilidade da classe. E que 6 a cada 8 da UFPB acreditam que tem contribuído, e apenas 2 acreditam que não. Porém, de acordo com Santos e Silva (2018, p. 688), o associativismo é um caminho no qual "os indivíduos unem esforços em defesa da categoria, promovem e ampliam o reconhecimento da profissão e se fortalecem para conquistar os direitos de sua categoria e as chances de alcançar os objetivos em comum".

Posteriormente, foi questionado: "Caso sua resposta tenha sido sim, quais atividades você destacaria como contribuição? E, caso sua resposta tenha sido não, de que maneira a AAPB poderia melhorar seu desempenho, quais atividades ela poderia executar visando contribuir com a Classe Arquivista?” As respostas serão apresentadas em um quadro a seguir, com exceção das respostas dos participantes E6 e E8, que não responderam, e do participante F4, que afirmou não conhecer a AAPB.

Quadro 1: Respostas dos participantes

\begin{tabular}{|l|l|}
\hline PARTICIPANTES & \multicolumn{1}{c|}{ RESPOSTAS } \\
\hline E1 & $\begin{array}{l}\text { "Só em ter dado um pontapé inicial na questão do olhar sobre a profissão já é muito } \\
\text { bom, apesar de ser muito discreta. Poderia ter um banco de dados com os registros } \\
\text { (curriculum) de todos os arquivistas formados na Paraíba, ter um certo controle sobre os } \\
\text { números; dar mais visibilidade, promovendo atividades, minicursos para os arquivistas. } \\
\text { Deveria ser a voz representante da classe. Entrar com recursos em casos de desrespeito à } \\
\text { legislação, como, por exemplo, o exercício ilegal da profissão, salário mínimo em } \\
\text { concurso público, etc. Enfim, se tivesse atributos visíveis na luta pelo direito e espaço do } \\
\text { profissional, atrairia muitos afiliados." }\end{array}$ \\
\hline E2 & "Expor mais." \\
\hline E3 & $\begin{array}{l}\text { "Acredito que ela tem contribuído através da realização de vários eventos, na divulgação } \\
\text { da área nos mais diversos meios de comunicação, na luta pela melhoria salarial do } \\
\text { profissional e ela proporciona uma maior união entre os profissionais da área através de } \\
\text { reuniões, eventos e entre outros." }\end{array}$ \\
\hline E4 & "Os eventos produzidos para contribuir com o aumento do conhecimento na área." \\
\hline
\end{tabular}




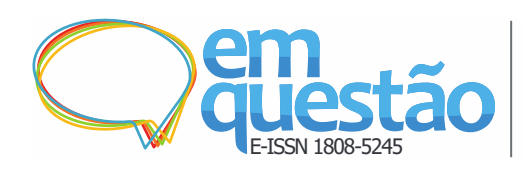

A importância da Associação dos Arquivistas da Paraíba como instrumento de fortalecimento e visibilidade profissional

Eloisa dos Santos Silveira, Claudialyne da Silva Araújo

\begin{tabular}{|c|c|}
\hline E5 & $\begin{array}{l}\text { "Buscando aumentar sua linha de convênios, confeccionando aos associados uma } \\
\text { carteirinha, facilitando reconhecimento de associado." }\end{array}$ \\
\hline E7 & "Fazendo eventos." \\
\hline E9 & "Promover cursos práticos relacionadas à área" \\
\hline E10 & "Organização do CNA." \\
\hline E11 & $\begin{array}{l}\text { "Ela está sempre empenhada e acompanhado as reivindicações dos arquivistas quando } \\
\text { se refere a piso salarial menor oferecido por alguns órgãos." }\end{array}$ \\
\hline E12 & $\begin{array}{l}\text { "Buscar possibilidades para aumentar o número de vagas de concurso que geralmente } \\
\text { não passam de duas, como também dar mais visibilidade à nossa profissão, pois, muitas } \\
\text { vezes, as empresas colocam um assistente administrativo para realizar o manuseio de } \\
\text { documentos (arquivamento) sem nem possuir uma formação para realizar tal tarefa." }\end{array}$ \\
\hline F1 & "Eventos como palestras, seminários, colóquios." \\
\hline $\mathrm{F} 2$ & $\begin{array}{l}\text { "Sou associada há } 16 \text { meses. No ano de } 2018 \text {, a AAPB foi a organizadora do VIII } \\
\text { Congresso Nacional de Arquivologia, cujo evento foi um marco para a arquivologia. Em } \\
\text { razão desse Congresso, vários outros eventos menores foram realizados para a promoção } \\
\text { daquele CNA. Além disso, sempre que a AAPB é chamada a resolver algum caso de } \\
\text { irregularidade como, por exemplo, em concursos públicos, ela se faz presente. As } \\
\text { maiores dificuldades da AAPB são pelo número muito pequeno de associados (o que se } \\
\text { traduz em escassos recursos financeiros) e por não dispor de uma sede definitiva com } \\
\text { espaço físico que permita a realização de eventos como cursos, grupos de trabalho, } \\
\text { treinamentos, rodas de conversa, etc. Também pelo fato de os membros da diretoria e os } \\
\text { associados não dispensarem um tempo maior à entidade dentro da justificativa e/ou } \\
\text { dificuldades/impedimentos de cada um. (Falta de tempo é o maior dos motivos - a } \\
\text { maioria trabalha em horário integral). A página da AAPB no Facebook é ativa. Com } \\
\text { publicações frequentes." }\end{array}$ \\
\hline F3 & $\begin{array}{l}\text { "A associação sempre que pode faz palestras, promove eventos, como foi o último } \\
\text { CNA" }\end{array}$ \\
\hline F5 & $\begin{array}{l}\text { "Busca desenvolver atividades que viabilizem o destaque e importância desse } \\
\text { profissional; promove eventos; sempre atualiza informações necessárias na atuação do } \\
\text { Arquivista." }\end{array}$ \\
\hline F6 & "Promoção de eventos da área." \\
\hline F7 & "Ajuda a fortalecer a classe arquivista." \\
\hline F8 & $\begin{array}{l}\text { "Dar publicidade às ações, pois, desde agosto de } 2018 \text { não houve qualquer publicação } \\
\text { que indicasse as ações da associação." }\end{array}$ \\
\hline
\end{tabular}

Fonte: Dados da Pesquisa, 2019.

De acordo com o exposto no quadro acima, podemos elencar, como principais contribuições da AAPB para com a classe arquivista, e apontadas pelos egressos: a organização e promoção de eventos, luta pela melhoria quanto a questões salariais do arquivista, e proporcionar uma maior união entre os profissionais da área através de reuniões, eventos, entre outros.

Dentre as principais sugestões apontadas como melhorias para a AAPB foram: publicizar mais suas ações, pois, de acordo com as respostas, a associação é muito discreta; criar um banco de dados com os currículos de todos os arquivistas formados na Paraíba; ser a voz representante da classe; tentar aumentar sua linha de convênios; confeccionar e disponibilizar aos associados uma carteirinha, com o intuito de facilitar o reconhecimento de associado; ter mais atributos visíveis na luta pelo direito e espaço do profissional arquivista, com vistas a atrair mais filiados. 
Quanto aos dados coletados junto à AAPB, o primeiro questionamento feito foi: "Qual o número de arquivistas Associados?" O R.A apontou que eles possuem apenas 22 arquivistas associados. A segunda pergunta realizada à AAPB foi: "Qual o número total de associados?" O R.A respondeu que eles possuem o total de 56 associados. Dessa forma, podemos perceber que o número de arquivistas associados não chega sequer à metade do total de associados.

Posteriormente, foi questionado: “Quais as categorias disponíveis para filiação?” O R.A afirmou que eles possuem cinco categorias, a saber: arquivista, técnico de arquivo, professor, estudante e empresa, o que demonstra que a AAPB se enquadra no tipo de associação categorizada por Souza (2011) como mista, que não possui como vinculados apenas arquivistas.

Levando em consideração que Souza (2011, p. 127) aponta que o principal objetivo das Associações Arquivistas “[...] é atuar em defesa da categoria nas diversas frentes de trabalho, organização de eventos, promoção de cursos", foi questionado como a AAPB tem atuado em defesa da categoria e o R.A exemplificou que a associação tem como compromisso principal a luta árdua pelo reconhecimento profissional e a incansável batalha por mais abertura no mercado de trabalho e por um espaço físico onde a AAPB possa desenvolver planejamentos, reuniões, cursos e grupos de estudo.

Além disso, apontou ter parcerias com uma empresa de advocacia, uma instituição para oferecer curso de encadernação e Curso Técnico de Arquivo, planos de saúde e parcerias de pós-graduação. Dessa maneira, podemos perceber que essa associação tem exercido o principal objetivo das associações arquivistas, o de atuar em defesa da categoria.

Diante dos dados que foram apresentados, podemos observar que os egressos respondentes, apesar de, em sua maioria, não serem filiados à $\mathrm{AAPB}$, consideram que ela tem contribuído com a categoria, em consonância com as respostas apresentadas pela Associação, que também apontou estar cumprindo o seu papel em defesa dos interesses da categoria.

\section{Considerações finais}

No decorrer desta pesquisa, foi possível atingir o principal objetivo deste trabalho: o de refletir sobre o associativismo arquivístico no estado da Paraíba. Assim, compreendemos um pouco mais o fenômeno do associativismo que, juntamente com o cooperativismo e o sindicalismo, constituem movimentos sociais em defesa dos interesses de um dado grupo social. 
Foi possível também perceber o quão relevante tem sido o associativismo para a Classe Arquivista. As associações profissionais no Brasil têm desempenhado um papel importantíssimo e, no que concerne à Arquivologia, também dizem respeito ao fortalecimento e reconhecimento da Classe.

A partir da análise e discussão dos dados, foi possível perceber que a maioria dos egressos acredita que o associativismo seja o principal caminho para que a Classe Arquivista ganhe força e visibilidade. Além disso, também a maioria conhece a Associação dos Arquivistas da Paraíba - AAPB e possui algum conhecimento a respeito da atuação dela em defesa da categoria.

Pôde-se perceber, através dos resultados, que a temática Associativismo Arquivístico deve ser abordada de forma mais recorrente e que devem haver mais discussões a respeito da importância dos coletivos profissionais e da atuação não apenas da AAPB, mas também do conhecimento de o quanto as associações arquivísticas são relevantes, a fim de reforçar sua contribuição com a classe. Ademais, importa ainda que essas discussões sejam publicizadas, para que o número de filiados às associações cresça e as mesmas possam ter um maior poder de representatividade, de modo que se torne possível a instituição de um Conselho Federal de Arquivologia, o qual irá fiscalizar o exercício da profissão e fortalecer a atuação dos arquivistas no mercado de trabalho.

Foi possível concluir também que existem poucas publicações sobre a temática na área Arquivística, o que fica em aberto para que sejam realizadas outras pesquisas a respeito do associativismo, fazendo essa ponte com a arquivologia e desenvolvendo estudos que relacionem questões como a falta de um órgão que fiscalize a profissão, pois, recentemente, foi lançada a Medida Provisória que retira a obrigatoriedade dos registros profissionais de algumas profissões, dentre elas a de Arquivista.

Finalmente, sugere-se que sejam realizados estudos a fim de investigar, por exemplo, a relação das associações com o ambiente universitário, se essa temática é recorrente aos discentes e se eles compreendem o papel que o associativismo exerce quanto a ser um movimento que atua em prol da categoria e que pode ser utilizado como uma forma de democracia.

\section{Referências}

ALMEIDA, Sonia Scoralick de; FEITOZA, Rayan Aramís de Brito; FELIX, Regia Sueli. PANORAMA DO ASSOCIATIVISMO DOS ARQUIVISTAS NA PARAÍBA. 
CONGRESSO NACIONAL DE ARQUIVOLOGIA - CNA, 8., 2018, João Pessoa. Anais eletrônicos... Revista Analisando em Ciência da Informação - RACIn, João Pessoa, v. 6, n. especial, p. 714-728, out. 2018.

ASSOCIAÇÃO DOS ARQUIVISTAS DA PARAÍBA-AAPB. Quem Somos: Nossa História. 2019. Disponível em: https://aapb.arq.br/. Acesso em: 10 abr. 2019.

BRASIL. Lei $\mathbf{n}^{\circ} \mathbf{6 . 5 4 6}$, de 4 de jul. de 1978. Dispõe sobre a regulamentação das profíssões de arquivista e de técnico de arquivo e dá outras providências. Brasília-DF, 1978. Disponível em: http://www.planalto.gov.br/ccivil_03/leis/1970-1979/L6546.htm. Acesso em: 9 maio 2018.

BRASIL. Lei $\mathbf{n}^{\mathbf{0}}$ 10.406, de 10 de janeiro de 2002. Institui o Código Civil. Brasília-DF, 2002. Disponível em: http://www.planalto.gov.br/ccivil_03/leis/2002/110406.htm. Acesso em: 18 maio 2019.

BRASIL. Lei $\mathbf{n}^{\mathbf{0}}$ 12.527, de 18 de novembro de 2011. Regula o acesso a informações previsto no inciso XXXIII do art. $5^{\circ}$, no inciso II do $\S 3^{\circ}$ do art. 37 e no $\S 2^{\circ}$ do art. 216 da Constituição Federal; altera a Lei $n^{\circ} 8.112$, de 11 de dezembro de 1990; revoga a Lei ${ }^{\circ}$ 11.111, de 5 de maio de 2005, e dispositivos da Lei $\mathrm{n}^{\circ} 8.159$, de 8 de janeiro de 1991; e dá outras providências. Disponível em: http://www.planalto.gov.br/ccivil_03/_ato20112014/2011/lei/112527.htm. Acesso em: 15 nov. 2019.

CALDERON, Wilmara Rodrigues et al. O processo de gestão documental e da informação arquivística no ambiente universitário. Ciência da informação, v. 33, n. 3, 2004.

CESÁRIO, Eliane Monteiro. Sindicato X Associação: entenda as diferenças. Sindicato Nacional de Servidores do Ministério de Relações Exteriores- SINDITAMARATY. 2017 Disponível em: https://www.sinditamaraty.org.br/comunicacao/noticias/7201-5-perguntassobre-. Acesso em: 30 out. 2019.

CONSELHO REGIONAL DE BIBLIOTECONOMIA - 15ª REGIÃO. Histórico. 2019. Disponível em: http://www.crb15.org.br/historico/. Acesso em: 26 out. 2019.

DALLARI, Dalmo. Viver em sociedade. 2014. Disponível em: https://www.aacademica.org/otavioluizmachado/54.pdf. Acesso em: 25 set. 2019.

FONSECA, Maria Odila Kahl. Arquivologia e Ciência da informação. Rio de Janeiro: Editora FGV, 2005.

HAHN LÜCHMANN, Lígia Helena. Abordagens teóricas sobre o associativismo e seus efeitos democráticos. Revista Brasileira de Ciências Sociais, v. 29, n. 85, 2014.

JODELET, Denise. Representações sociais: um domínio em expansão. As representações sociais, p. 17-44, 2001.

MARQUES, Angelica Alves da Cunha; RODRIGUES, Georgete Medleg; NOUGARET, Christine. Arquivos e Arquivologia na França e no Brasil: marcos históricos e contextos singulares. Revista Brasileira de História, São Paulo, v. 38, n. 78, p. 17-38, maio/ago. 2018. 
Eloisa dos Santos Silveira, Claudialyne da Silva Araújo

MICHEL, Maria Helena. Metodologia e Pesquisa em Ciências sociais: Um guia prático para acompanhamento da disciplina e elaboração de trabalhos monográficos. 2. ed. São Paulo:

Atlas. 2009.

REIS, Luis. O arquivo e arquivística evolução histórica. Biblios: Revista Electrónica de Bibliotecología, Archivología y Museología, ed. Lima, Perú, v.7, n. 24, 2006.

SANTOS, Sonia Luiza Freitas dos; SILVA, Késsia Karla Portela Richene. Associativismo e Visibilidade Profissional: reconhecendo o papel do arquivista na sociedade. Congresso Nacional de Arquivologia - CNA, 8., 2018, João Pessoa. Anais Eletrônicos... Revista Analisando em Ciência da Informação - RACIn, João Pessoa, v. 6, n. especial, p. 682-696, out. 2018.

SERVIÇO BRASILEIRO DE APOIO ÀS MICRO E PEQUENAS EMPRESAS- SEBRAE. Associativismo: as principais diferenças entre associação e cooperativa. 2019. Disponível em: http://www.sebrae.com.br/sites/PortalSebrae/artigos/artigosCoperacao/entenda-as-diferencasentre-associacao-e-cooperativa,5973438af1c92410VgnVCM100000b272010aRCRD. Acesso em: 30 out. 2019.

SERVIÇO BRASILEIRO DE APOIO ÀS MICRO E PEQUENAS EMPRESAS- SEBRAE. Associativismo: o que é?. 2019. Disponível em: http://www.sebrae.com.br/sites/PortalSebrae/ufs/ap/artigos/associativismo-o-quee,01353ea344900610VgnVCM1000004c00210aRCRD. Acesso em: 08 mar. 2019.

SERVIÇO NACIONAL DE APRENDIZAGEM RURAL- SENAR. Curso técnico em agronegócio: associativismo, cooperativismo e sindicalismo. Brasília: SENAR, 2015. Disponível em: http://senar-es.org.br/doc/uc/UC \%2012\%20-

$\% 20$ Associativismo, \%20Coperativismo\%20e\%20Sindicalismo.pdf. Acesso em: 11 fev. 2019.

SOUZA, Katia Isabelli Melo de. Arquivista, visibilidade profissional: Formação, Associativismo e Mercado de Trabalho. Brasília: Starprint, 2011.

Arquivologia UEPB. Histórico. Disponível em: http://arquivologiauepb.com.br/curso/historico/. Acesso em: 18 de set. 2019.

\title{
The importance of the Association of Paraíba Archivists in improving archivist professional visibility
}

\begin{abstract}
This study aims to assess the importance of professional association in the state of Paraíba, in Northeast Brazil. It highlights how professional archivists associations have been discussed more frequently among the archivist community and how they have come to be regarded as the main way to strengthen that professional class and to increase its visibility. This study surveyed archivists who graduated from 2015 to 2018 from Paraíba State University (Universidade Estadual da Paraíba, UEPB) and from the Federal University of Paraíba (Universidade Federal da Paraíba, UFPB), as well as archivists affiliated to the
\end{abstract}


Association of Paraíba Archivists (Associação de Arquivistas da Paraíba). It adopts both qualitative and quantitative approaches and is descriptive in nature. Data were collected through Google Forms surveys, sent to the informants by email. The informants indeed regarded professional association as the main way to further the interests of Paraíba archivists, but remarked that the number of members of the Association of Paraíba Archivists was still relatively low, which they attributed to inefficient or insufficient advertisement.

Keywords: Associação dos Arquivistas da Paraíba. AAPB. Archivist. Paraíba. Professional association. Professional visibility.

Recebido: 24/04/2020

Aceito: $17 / 07 / 2020$

\section{Declaração de autoria}

Concepção e elaboração do estudo: Eloisa dos Santos Silveira e Claudialyne da Silva

Araújo

Coleta de dados: Eloisa dos Santos Silveira e Claudialyne da Silva Araújo

Análise e discussão de dados: Eloisa dos Santos Silveira e Claudialyne da Silva Araújo

Redação e revisão do manuscrito: Eloisa dos Santos Silveira e Claudialyne da Silva Araújo

\section{Como citar}

SILVEIRA, Eloisa dos Santos; ARAÚJO, Claudialyne da Silva. A importância da Associação dos Arquivistas da Paraíba como instrumento de fortalecimento e visibilidade profissional.

Em Questão, Porto Alegre, v.27, n. 1, p. 111-131, 2021. Doi: http://dx.doi.org/ $10.19132 / 1808-5245271.111-131$ 